\title{
Depoimento de Esdras Borges Costa: Revisitando Itapetininga, "Freguesia" e o Vale do São Francisco
}

\author{
Esdras Borges Costa
}

Esdras Borges Costa nasceu em 18/07/1929, na cidade de Araraquara, no interior de São Paulo. Sociólogo graduado pela Escola Livre de Sociologia e Politica em 1951, participou do Projeto do Vale do Sáo Francisco, coordenado por Donald Pierson na década de 1950. Doutorou-se em sociologia pela Universidade da Califórnia, Berkeley em 1979, com "Protestantismo, Modernização e Mudança Cultural no Brasil", sob a orientação de Robert N. Bellah. Fez carreira como professor universitário na FGV (Fundação Getúlio Vargas) em São Paulo. Esdras é um dos fundadores do PSDB (Partido da Social Democracia Brasileira). Atualmente pesquisa o desenvolvimento das religióes protestantes no Brasil.

Inicialmente eu gostaria de agradecer o convite pela oportunidade de relembrar coisas que aconteceram com um jovem sociólogo e que foram tão marcantes na minha trajetória. $\mathrm{Eu}$ sinto que a professora Josildeth [Gomes Consorte] e o professor João Baptista [Borges Pereira] não estejam aqui presentes porque me lembro deles desde a Escola de Sociologia e Política que era um centro muito vivo, muito ativo e muito modernizador. Vinha gente de fora, era um ambiente de pesquisa bastante ativo. Antes do [Projeto do Vale de] Sáo Francisco fiz pesquisa de mercado - foi no tempo em que surgiram as pesquisas de mercado aqui em São Paulo. O professor Octávio da Costa Eduardo, que era meu orientador, foi primeiro nessa área. Nesta época, andei muito pela cidade, terminei a graduação e comecei a fazer a pós-graduação, que foi organizada pelo professor Donald Pierson.

Vocês sabem que os estudos de comunidade são muito criticados e sempre foram. $\mathrm{Na}$ época [entre os anos 1940-1960] eram considerados como um tipo de "método", um tipo de atividade científica que tinha alguns problemas em ser ciência. Com a sociologia e a antropologia isso não se dava, [pois elas] utilizaram muito os métodos quantitativos e os estudos de comunidade sempre foram, assim, uma espécie de "primo pobre" [das ciências sociais]. Eu acho muito importante que vocês tenham dado o título de "Constituindo um campo" a este evento porque nós temos que fazer isso na ciência a todo momento. Nas ciências sociais temos que constituir e reconstituir o campo a todo momento porque há muito desgaste, os métodos vão mudando e as pessoas vão mudando. Os estudos de comunidade têm sido muito criticados, mas nesta exposição não pretendo discutir diretamente as críticas propriamente ditas.

Há um problema básico que é o de se saber "o que é" estudo de comunidade. É uma questáo difícil e sempre tive muito interesse neste tipo de estudo porque é variado, heterogêneo, envolve atitudes diferentes, campos diferentes, métodos e técnicas diferentes. Mas a pergunta é: será que os estudos de comunidade realmente têm sua própria natureza ou será que são auxiliares de outros métodos? Será que é possível utilizá-los na pesquisa científica, na discussão científica? Saber o que é estudo de comunidade, como método e como projeto, 
é uma questão central. Foi o Oracy Nogueira que formulou a noção mais compreensiva e sistemática dos estudos de comunidade. Isso em seu texto de 1955, publicado na Revista de Antropologia ${ }^{2}$.

Eu gostaria de começar minha exposição tratando de algumas noções classificatórias, como "história e estrutura", ou se quiserem, "evolução histórica e estruturas sociais”. As outras [noçōes] são a de "generalizações empíricas", "descrição estatística" e de "configuração social"3. Nesta fala utilizarei essas classificaçóes na leitura seletiva de três monografias. Uma é do professor Oracy Nogueira [Familia e comunidade: um estudo sociológico em Itapetininga], minha referência principal, e dois trabalhos de minha autoria. Um que foi publicado [Cerrado e Retiro: cidade e fazenda no alto Sáo Francisco] e outro que não [sua monografia sobre "Freguesia"] ${ }^{4}$.

Depois, eu gostaria de discutir com vocês algumas questóes de método e a possibilidade de uma proposta de narrativa etnográfica. Tudo em referência aos estudos de comunidade. Estou tomando narrativa como substantivo, correspondente à ação de narrar, de contar histórias, de contar o que aconteceu. Essas categorias são pontos que deveráo servir para uma classificação dos parágrafos e das situaçóes que vou apresentar [presentes nos três estudos citados].

Meu interesse é saber o que há sobre a evolução de estruturas sociais, o que há de descrições e de generalizações empíricas nesses trabalhos. Dizer que as pessoas se comportam da seguinte maneira; que a família é estruturada da seguinte maneira; que a estrutura social inclui tantas e tantas classes são afirmações gerais, são generalizações empíricas. Mas, como esses itens se articulam? Eu tenho a impressão que eles estão numa ordem de crescente complexidade. Você pode fazer descriçóes ou generalizações empíricas sobre um determinado grupo sem pensar na sua história. Sem pensar, sem imaginar que esse tipo de família, esse tipo de economia, tiveram uma história. Você pode também fazer histórias, historiografia sem se preocupar em falar da estrutura, qual a estrutura existente. Em ciências sociais e para os estudos de comunidade é necessário saber a história das estruturas existentes. Por exemplo, de onde surgiu essa família? Nem sempre é possível se saber, mas do ponto de vista metodológico é necessário se perguntar. As estruturas sociais têm sua história, têm sua "idade" e não duram para sempre. Sem este pressuposto, um estudo de comunidade pode se tornar "reificante" ou "tautológico".

[Itapetininga]

No começo de seu livro sobre Itapetininga, Oracy [Nogueira] afirma: [lendo o início da citação] A luta pela terra faz história a partir de fins do século XVII, com nomes, dados, lugares, envolvendo brancos e pretos, libertos e mesmo escravos. Durante toda história do município a atuação da sucessão igualitária e da alienação comercial, no sentido da fragmentação da propriedade fundiária, tem sido contrabalançada por uma variedade de fatores. $\mathrm{O}$ casamento entre parentes, intraclasse, o predomínio, de fato, de um herdeiro sobre os demais (...). Graças a todos esses fatores, o latifúndio tem logrado persistir como a pedra angular de um sistema extensivo e rudimentar (aqui ele está começando a falar de história e de estrutura), tanto de pecuária como de agricultura em que todas as desvantagens têm militado contra o pequeno proprietário. (Neste ponto surge uma proposta analítica, uma proposta prática e política, inclusive). Desfazendo-se e recompondo-se, contraindo-se para de novo se expandir, é como se a propriedade fundiária fosse dotada - na expressão de um observador local - de uma verdadeira capacidade de pulsação [fim da citação].

Oracy continua nesse primeiro trabalho falando da distribuição e da exploração da propriedade fundiária, da terra, e ele utiliza estatística e descriçóes estruturais em suas análi- 
ses. Depois ele analisa também a vida na zona rural e descreve o comportamento das pessoas na agricultura, na organização do trabalho, na organização da família, na relação entre os herdeiros e os não herdeiros.

Uma das críticas aos estudos de comunidade é a de que estes estariam submetidos a uma preocupação prática de planejamento, de assessorar organismos de planejamento e de desenvolvimento. E na monografia de Oracy isso aparece claramente. $\mathrm{O}$ último capítulo [de seu livro] é sobre educação formal. É um capítulo que ele escreveu no tempo em que ele estava trabalhando para o CBPE, o Centro Brasileiro de Pesquisas Educacionais, e estava envolvido num projeto de planejamento educacional. Nesse capítulo ele fala de educação formal da seguinte maneira: "Da primeira à última fase histórica, um mesmo complexo de atitudes, tanto por parte dos pais, como dos mestres, tem condicionado, mais do que qualquer filosofia educacional explícita, as atividades escolares”. E então, ele passa a uma descrição que eu estou chamando de descrição estrutural: "A educação formal, da elementar à superior é vista, sobretudo, como um mecanismo de ascensão e de consolidação do status social, através do qual, o educando, por si ou por seus responsáveis procurava libertar-se do trabalho manual, pesado ou sujo, constituindo cada nível de ensino um passo para o seguinte. As atividades escolares continuam sendo marcadamente verbalistas e intelectualistas, acadêmicas e seletivas, concentrando-se os esforços de mestres e educandos, no treino para os exames como caminho para a conquista dos certificados e diplomas". Mais adiante, ele diz que "a educação tradicional resiste no ceticismo de colegas, professores e alunos, além da rigidez do sistema altamente centralizado e burocratizado em que tem que trabalhar, forças essas que obrigam os professores inovadores a contrariar na prática, o que preconizam em princípio". Nestes parágrafos coexistem referências àquele "complexo de atitudes" a que ele se referiu no início e, por outro lado, a acontecimentos e hábitos que podem ser chamados de história do presente - o que estava acontecendo na época do estudo, no sentido de relatos e acontecimentos ocorridos no tempo da monografia, que foi mais ou menos de 1947 até 1956, nove anos, durante os quais esse trabalho foi elaborado por Oracy. Nessas páginas o texto se torna, por assim dizer, mais concreto, pois além de ser um relato de pesquisa, sugere - ainda que implicitamente - uma atuação prática no sentido da inovação educacional. Esse estilo marca o capítulo inteiro, deste que, como se sabe reflete o trabalho do autor junto ao CBPE. Neste parágrafo de análise há uma subordinação da estrutura à história, no sentido de que a estrutura que está posta tem uma história.

Agora, o Oracy também utilizava dados estatísticos em suas críticas. Alguns indicam que os estudos de comunidade tinham muita estatística, outros acham que tinham pouca e insuficiente. Isso se deve ao fato de que nos anos 1960-1980, no mundo inteiro, há um crescente prestígio das pesquisas estatísticas, os surveys - com a aplicação de questionários e os cálculos indicando com números quais as características de uma determinada estrutura social. Então, como é aparecem as estatísticas no texto do Oracy? Em primeiro lugar, além das estatísticas oficiais e censitárias, Oracy também fez o seu próprio levantamento demográfico. Em vários parágrafos, por exemplo, sobre o lugar $\mathrm{da}$ mulher, sobre o status da mulher, sobre as ocupações, ele realizou uma articulação entre as estatísticas e as configuraçóes sociais. As estatísticas apareciam ou para confirmar a estrutura da família, de acordo, por exemplo, com a assimetria da idade dos noivos no casamento para indicar a diferença entre homens e mulheres. $\mathrm{Na}$ estatística ocupacional os números estavam ligados à caracterização das estruturas e subestruturas sociais de Itapetininga. 
304 EsDras Borges Costa

Esse estudo durou nove anos e passou por quatro ou cinco filiaçóes do autor a instituiçôes. Ele usou os primeiros dados como professor da Escola de Sociologia e Política para suas aulas. Depois ele trabalhou num estudo para a UNESP [Universidade Estadual Paulista], depois trabalhou no Instituto de Administração aqui na Faculdade de Economia [da USP] e foi trabalhar no CBPE [Centro Brasileiro de Pesquisas Educacionais], do Instituto Nacional de Pesquisas Educacionais, no tempo do Anísio Teixeira.

Quais foram os limites da comunidade que Oracy estudou? Esse é outro ponto que aparece nas críticas, qualquer pesquisador de estudos de comunidade terá que enfrentar isso em alguma hora: você tem que delimitar a comunidade em estudo. Porque tudo o que você vai discutir é sobre aquela comunidade específica. Então, quais são esses limites? Os limites conhecidos, mais ou menos, como município de Itapetininga, foram evoluindo, foram mudando. E numa das passagens do Oracy existe uma discussão sobre o que é comunidade. O que é a comunidade quando você vai fazer um estudo de comunidade? Quais são os seus limites? Qual é o seu perímetro?

É claro que isso é definido, não apenas espacialmente, mas também pelas relações sociais. Então, até que ponto determinado grupo ainda está ligado à sociedade da comunidade que estou estudando? Até que ponto já não está mais? Dentro da comunidade há pessoas não ligadas à comunidade como muitas outras são. Agora, qualquer estudante de comunidade não vai poder passar sem conjunto de estruturas, de pessoas, grupos que constituem o seu objeto de estudo. Eu acho que um dos problemas, que eu também tive quando fui fazer minhas pesquisas, era saber se é possível colocar ou não determinada extensão da comunidade para dentro ou para fora do estudo.

[Freguesia]

Com isso passo para a segunda pesquisa. Que deve ser um pouco mais rápida para mim porque é minha própria experiência [risos], que foi numa vila de pescadores na ilha de Santa Catarina. Essa comunidade, que eu chamei de "Freguesia", tinha aproximadamente mil pessoas, aproximadamente duzentas casas e era bastante isolada. Naquele tempo levava meio dia para chegar até lá, hoje você vai em meia hora, mas o lugar era realmente isolado. Nessa comunidade eu fiz a pesquisa sozinho. O que traz, evidentemente, uma série de problemas: como você vai ser controlado nos seus erros e nas suas classificações?

Nesse estudo, eu acabei sendo levado a olhar a comunidade em termos dos seus calendários. À medida que fui lendo o que escrevi, vi que dei importância aos calendários. Comecei analisando o calendário diário, anual e no fim descobri que o importante era o calendário econômico. A fabricação da farinha, a época da tainha e assim por diante. E, por outro lado, o calendário religioso: dos santos, das festas. A grande preocupação do pessoal da "Freguesia", era a fabricação da farinha de mandioca e a pesca da tainha. Na época da tainha e da mandioca a comunidade estava muito mais ocupada, mais segura de si, porque aquilo representava sua segurança econômica - e ela era uma comunidade muito pobre, realmente muito pobre - e também mais sensível às festas religiosas, que é o sentimento religioso, de celebração ou de solicitação de ajuda ou de manifestação da comunidade como uma comunidade coesa.

Em "Freguesia", eu visitei todas as casas, fiz um censo da população, um recenseamento das casas, dos seus móveis, das suas peças, dos seus pertences, mas isso não foi incluído no relatório. Fui hospedado pela família mais forte do lugar, que mandava realmente bastante, e aqui cabe uma observação: como ocorre em muitas comunidades brasileiras a estrutura da comunidade dependia muito da estrutura da família. Havia então, parentes de vários lados, parentes 
fortes e parentes fracos, parentes do PSD [Partido Social Democrático] e da UDN [União Democrática Nacional]. Eu fui hospedado numa casinha perto da escola e lá fiquei vários meses.

Eu queria dizer a vocês que foi um envolvimento muito grande. Eu nem imaginava isso, eu era muito jovem e, aos poucos, fui ficando cada vez mais incluído na comunidade e náo sei o quanto isso afetou as observaçôes. Tentei ser crítico, mas continuei mantendo o meu esforço de observar, orientado de longe pelo professor Octávio da Costa Eduardo.

Eu sou protestante e aquela vila era de uma religião só, era católica - catolicismo rústico, catolicismo pouco institucionalizado, mas entâo eu pude sentir um pouco a crise de ter que absorver alguém estranho, numa comunidade em que a religião era extremamente importante. Aos poucos isso foi andando, andando e no fim acabei sendo convidado para ser padrinho de uma criança, só que o padre disse: "olha ele pode ser padrinho, mas a madrinha tem que ser católica”. [risos]

A comunidade de "Freguesia" foi escolhida por qual razão? Porque naquela época havia curiosidade a respeito dos imigrantes açorianos no Brasil. Antes de ir para lá fiquei sabendo que há imigrantes açorianos em toda a parte do mundo, no sul do Brasil eles foram muito importantes. Parece que pelo menos os da primeira imigração foram para Florianópolis - que se chamava Desterro - ainda no século XVII. Mas aqui tenho uma autocrítica em relação à minha pesquisa histórica: não fiz história o suficiente. Bem, eu acabei voltando lá depois de vinte anos e estou desconfiado que aquela vila resultou de uma re-imigração de açorianos que vieram do Rio Grande do Sul. Por que isso é importante? Eu imagino que o que aconteceu em "Freguesia" foi influenciado pela experiência anterior dos antepassados que teriam vindo do Rio Grande do Sul. Por outro lado, trata-se de uma segunda migração.
A partir dessas experiências e do livro do Oracy a gente se pergunta o quanto as afirmações gerais de estruturas revelam a realidade. $\mathrm{O}$ que é uma preocupação do cientista em qualquer lugar: "quanto daquilo que eu estou dizendo do que se passou revela a realidade?" Se eu digo que a família dominante é centrada no latifúndio e no chefe da família, estou fazendo uma afirmação geral. Uma afirmação que é analítica, que envolve história, que envolve estrutura e assim por diante, será que isso corresponde à verdade?

[Vale do São Francisco: Cerrado e Retiro]

$\mathrm{Eu}$ queria insistir nesse ponto. Quando você vai ler os relatos, fica sempre se perguntando quanto o que está escrito reflete o que se passa na comunidade. Por isso eu acho que o segundo estudo que eu fiz lá, na cidade de Cerrado foi um pouco mais seguro, porque nós éramos uma equipe de cinco pessoas. Eram duas mulheres e três homens; um destes era jornalista e o outro era padre - que por sinal pôde verificar várias coisas que não poderíamos observar e não pôde observar algumas outras que nós podíamos observar, por causa das proibiçôes sociais. Mas a pergunta que permanece é: de que forma aquilo que está escrito reflete o que se passa?

Então eu queria propor para vocês uma questão, um problema. Eu tenho a impressão de que se você contar histórias, você tem um pouco mais de possibilidade de contar o que se passou. Isso é uma hipótese. Porque se você conta história, um caso que ocorreu de fato, você tem atores, pessoas identificadas, lugares, você tem o tempo, você tem um enredo e tudo isso pode ser verificado. Uma narrativa pode ser realmente um reflexo de uma realidade muito rica. Eu gostaria de narrar para vocês alguns acontecimentos lá da "Freguesia". Certa vez, eu viajei com algumas pessoas numa canoa. Há uma lagoa no meio da ilha [de Florianópolis] que é muito grande e nós atravessamos naque- 
la canoa, barquinho com vela e o responsável pela canoa era um pescador. O leme da canoa era um remo que roda assim [mostra como o leme era movido]. Então, nós saímos de um lado com o tempo muito bom, mas quando foi chegando no meio da lagoa, que é muito grande, começou a ventar, começou a ter realmente muito perigo e, nesse momento, - veja eu estou contando para vocês uma história que realmente aconteceu - nesse momento todo mundo, inclusive eu, ficamos com medo. Vamos naufragar! Mas preocupados com a capacidade do capitão, único que sabia manobrar aquela canoa. Então toda a técnica que ele tem de pescador experimentado, estava ali em xeque. E é dessa técnica que estava dependendo as nossas vidas. Muito bem. As pessoas no começo da viagem estavam cantando, brincando; quando começou essa situação começaram a quê? Começaram a rezar [risos], virou o tempo na canoa. Felizmente chegamos do outro lado da lagoa onde havia uma festa. Isso ocorreu mesmo, essas pessoas são pessoas concretas; não são generalizações, estruturas, são pessoas concretas, há um enredo. Há muitos desses enredos, há muitos desses acontecimentos no diaa-dia. Claro, ocorrem coisas mais importantes, menos importantes evidentemente. Mas, o que eu estou propondo é usar, de vez em quando narrativas, pois você tem clareza sobre o que pode e o que não pode ser uma comunidade quando você usa uma narrativa na pesquisa.

Numa das noites (eu voltava sempre cedo para casa) eu simplesmente fui visitar uma família e fiquei batendo papo com eles o tempo todo e náo voltei para casa. Os meus hospedeiros ficaram preocupadíssimos e eu caí das nuvens, pois pensava não haver perigo algum. Meus hospedeiros ficaram muito preocupados, creio que ficaram com ciúmes. Outra coisa que eu queria contar para vocês também: o pesquisador acaba sendo objeto de afetividade diferenciada e sua ação vai sendo mandada, vai sendo orientada, vai sendo dominada por algumas dessas diferentes emoções [...].

Agora eu quero sair do debate sobre narrativa e passar para uma outra abordagem, para um outro ponto de vista que volta a ser um ponto de vista estrutural. $\mathrm{O}$ calendário, o ritmo religioso, o ritmo econômico e a estrutura alimentar daquele povo estavam muito relacionados. Eles dependiam de tainha, quando houvesse; quando náo houvesse era farinha de mandioca, pirão. Está registrado aí o que eles chamam de padrão do pirão, ou seja, a comida fundamental tem um certo valor, uma certa interpretaçáo na sociedade. Então quando os higienistas falam que o pessoal da zona rural não come verdura, não come fruta, sem dúvida, mas essa preferência por determinados alimentos faz parte dos valores da estrutura da sociedade, isso está relacionado com a estrutura de produção. Então, por exemplo, quando é época de tainha todo mundo está muito animado, porque você tem fartura de alimento, tem a farinhada. Então, há uma articulação entre a estrutura alimentar, a estrutura econômica e a estrutura religiosa da comunidade.

Agora eu passo a falar sobre o que está no programa de vocês, sobre a pesquisa do Vale do São Francisco. Nessa pesquisa nós éramos uma equipe de cinco pessoas, em uma cidade pequena e num conjunto de fazendas no Alto do São Francisco. Relendo Cerrado e Retiro percebo que no livro há uma predominância de um conceito, um eixo, que é o eixo rural-urbano. A preocupação era saber quão urbana e quão rural a comunidade era naquele tempo. Há em todos os capítulos essa preocupação de saber até que ponto Cerrado era uma cidade completamente urbanizada ou ainda rural. As fazendas eram completamente rurais ou já estavam em contato com o mundo externo? Isso mantém a unidade da estrutura do texto, da descrição e das generalizações empíricas da pesquisa. 
Há dois ou três capítulos em que está documentada a preocupação com a estratificação social. Toda ênfase desse relatório é que está havendo lá uma tensão social, uma tensão de estratificação social. As classes não estavam mais seguras da sua posição. Havia um pequeno clube de recreação em que isso aparecia claramente, mas a estrutura de classe estava em dúvida, havia pessoas que não sabiam mais se pertenciam à classe superior ou não. A classe dos fazendeiros estava sendo questionada, havia os negros e os empreiteiros rurais que já não estavam assim tão subordinados às decisões de fazendeiros e assim por diante. Era clara uma época de tensão da estratificação social. Há um capítulo também sobre religião, e aí não há muita novidade, eles eram de religião católica rústica, havendo alguma diferenciação religiosa, mas pouco explícita.

Cerrado e Retiro foram escolhidas no survey que o professor [Donald] Pierson e Octávio da Costa Eduardo fizeram em todo Vale do São Francisco, realizando o levantamento de uma série de comunidades. Eu me lembro que houve dúvidas sobre a escolha [de Cerrado] porque havia uma cidade mais próxima que era mais antiga e a dúvida séria era se a gente escolheria essa cidade mais nova ou a cidade mais velha, mais antiga. No fim ficamos com essa e eu tenho a impressão que isso marcou bastante o estudo. Mas a outra questão da escolha das comunidades era saber se Cerrado e Retiro representariam o Alto São Francisco, aquela regiáo que é tomada hoje pela barragem [de Três Marias].

No último capítulo do livro levanto outra questão: será que Cerrado e Retiro eram duas comunidades ou eram a mesma comunidade? Retiro era um conjunto de fazendas que ficava uns trinta, quarenta quilômetros fora da cidade. Essa foi uma dúvida clara, mas foi uma dúvida que eu levantei depois de ter organizado a maior parte dos dados nestes termos: Cerrado tem uma estrutura ocupacional urbana, edu- cação urbana, recreação urbana, estratificação social urbana. Retiro, não! Lá você tem a economia rural, as fabricações são muito mais simples, a família muito mais firme, os trabalhadores da roça muito mais subordinados ao fazendeiro, ao mesmo tempo que mais ligados a ele afetivamente, porque vão à casa da fazenda toda noite para conversar, assim por diante. Assim, o contraste foi forte. Por isso, é preciso ficar atento para a história do que está acontecendo. Será que estava havendo uma reconstituição da economia rural na comunidade,? Ou será que houve uma absorção total da economia rural na cidade?

Já "Freguesia" era uma vila em que todas as famílias tinham uma rês, todas, mais pobres ou mais ricas, tinham a sua roça de mandioca e mandavam o leite para fora para ganhar algum dinheirinho. Então havia uma grande homogeneidade nas atividades rurais e urbanas, mas não havia uma continuidade econômica, isso não! O controle econômico, financeiro, destas atividades variava bastante. Realmente havia concentração de riqueza, mas a distribuição econômica era principalmente rural, [apesar de haver] atividades urbanas também na regiāo. Eu acho que "Freguesia" era quase inteiramente rural, apesar de influências da cidade. Por exemplo, os partidos políticos dentro da vila reproduziam as atividades dos partidos políticos da capital. Havia pessoas da vila, das famílias da vila, que estavam morando fora há muito tempo. Então a vila tinha contatos com a cidade, e tinha alguns comportamentos urbanos. Por exemplo, algumas pessoas iam para fora da vila estudar: voltavam com toda a influência urbana das escolas urbanas, mas a estrutura econômica e social da vila era realmente rural $[. .$.$] .$

Enfim, é isso que queria compartilhar com vocês. Agradeço porque foi uma oportunidade de ir às minhas anotaçóes, aos relatórios, às leituras e aos arquivos. Relembrando tudo isso, 
me recordo que nessa época meus pais, naturalmente acharam que estudar sociologia não fazia sentido. Mas eu estava naquele bom tempo dos ideais da mocidade, de querer transformar o mundo. Eu achava que a sociologia salvaria o mundo. Que as ciências sociais seriam úteis para resolver alguns dos nossos problemas [...].

\section{Notas}

1 "Constituindo um Campo": estudos de comunidade e o desenvolvimento das Ciências Sociais no Brasil (19401960) foi o título do evento organizado, em 18 set. 2009, na FFLCH/ USP, no qual o Professor Esdras Borges Costa realizou a conferência ora transcrita e editada pela Cadernos de Campo para a publicaçáo neste especial. $\mathrm{O}$ texto é apresentado com algumas modificações das editoras, tais como, a inserção de notas explicativas e informaçóes que aparecem entre colchetes ao longo do texto, além de outras adequaçōes da linguagem oral para o texto escrito.

2 NOGUEIRA, Oracy. Os Estudos de Comunidades no Brasil, Revista de Antropologia, vol. 3 (2), p. 98-99, 1955.

3 Embora o professor Esdras afirme que não pretenda discutir as críticas propriamente ditas, percebe-se em sua fala um diálogo com questôes postas no debate entre os anos de 1950 e 1960. Entre estas posiçōes divergentes na época, é possível notar um diálogo direto com as formulaçóes de Gioconda Mussolini no texto Persistência e mudança em sociedades de folk no Brasil, republicado neste especial.

Seu depoimento tem como base os comentários de três monografias: NOGUEIRA, Oracy. Família e comunidade: um estudo sociológico em Itapetininga Rio de Janeiro: Ministério de Educação e Cultura, Instituto Nacional de Estudos Pedagógicos, Centro Brasileiro de Pesquisas Educacionais [Série Sociedade e Educação, Coleção Brasil Provinciano], 1962; COSTA, Esdras Borges. Cerrado e Retiro: cidade e fazenda no alto Sáo Francisco. Rio de Janeiro: Comissão do Vale do São Francisco, 1960; e a sua monografia não publicada sobre "Freguesia", realizada enquanto era aluno da Escola Livre de Sociologia e Política, sob a orientação do professor Octávio da Costa Eduardo, em 1951.

5 "Freguesia" aparece aqui entre aspas porque é o nome fictício da comunidade estudada pelo professor Esdras, em Santa Catarina. Este procedimento de não revelar o nome verdadeiro do município ou localidade estudada é algo corriqueiro nos trabalhos desta tradição de estudos de comunidade. Ao utilizar um nome fictício, o que se pretendia era preservar a comunidade e seus habitantes, tanto que ainda hoje Esdras refere-se à esta localidade estudada apenas como "Freguesia".

autor

\title{
Esdras Borges Costa
}

Professor de Sociologia/FGV

Doutor em Sociologia/ Universidade da Califórnia, Berkeley

\author{
Recebida em 18/09/2009 \\ Aceita para publicação em 18/09/2009
}

